\title{
ANTIVIRALS FOR VIRUS INDUCED EXACERBATIONS OF ASTHMA AND COPD TREATMENT
}

\section{Grigorescu Gristina1, Antoniu Sabina Antonela1, Oțelea Marina Ruxandra², Ileana Antohe', Fildan Ariadna Petronela ${ }^{3}$, Arghir loan Anton. ${ }^{3}$, Tofolean Ecaterina Doina ${ }^{3}$}

${ }^{1}$ University of Medicine and Pharmacy "Gr. T. Popa", Iasi, Romania

${ }^{2}$ University of Medicine and Pharmacy "Carol Davila", Bucharest, Romania

${ }^{3}$ Faculty of Medicine, University "Ovidius" of Constanta, Romania

\begin{abstract}
Viral respiratory infections in patients with asthma or chronic obstructive pulmonary disease (COPD) can cause severe exacerbations, increasing the risk of secondary bacterial infections and having a significant impact on disease-related morbidity and mortality. Several antivirals such as oseltamivir and zanamivir evaluated in influenza and other virus-induced respiratory infections are discussed in this review as a starting point of their potential use in improving the outcome of asthma and COPD exacerbations. However, the efficacy of antiviral therapy for asthma/ COPD exacerbations needs a further evaluation.
\end{abstract}

Keywords: antiviral therapy, asthma, COPD, oseltamivir, zanamivir

\section{Introduction}

Chronic obstructive pulmonary disease (COPD) and bronchial asthma are both obstructive lung disease (OLD) with inflammatory pattern of the airways. Respiratory infections can be caused by viruses or bacteria and induced COPD or asthma exacerbations with steeply aggravated dyspnea and/or cough with sputum production, episodic bronchospasm and wheezing, mainly in smokers $(1,2)$. Symptoms are, usually, controlled with inhaled corticosteroids and long-acting bronchodilators, which are able to reduce the airways inflammation and relieve the bronchospasm in a sustained manner (3). Viruses have been reported in $\geq 30 \%$ of exacerbations in COPD patients, respiratory syncytial virus (RSV), rhino-(RV) and influenza viruses (IV), being the most detected strains $(4,5)$. In exacerbations of asthma, viral infections are commonly detected in children $(6,7)$, especially, in unvaccinated ones (8).

The aim of this review consists in summarizing the existing data on the available antiviral therapies for the most common viruses involved in asthma and COPD exacerbations and discussing the potential indications. 


\section{Asthma and COPD with viral exacerbation: how to define the most appropriate target population requiring an antiviral therapy}

In COPD patients, viral respiratory infections or combined viral-bacterial infection can have a significant impact on diseaserelated morbidity by determining more severe exacerbations (9-11). Rhinoviruses are the most prevalent viral strains isolated in COPD patients with severe respiratory symptoms and a longer duration of recovery after exacerbation (12). Chronic viral infection can "open the door" for chronic bacterial infections COPD-related, by interfering with endogenous bactericidal mechanisms (13). Persistent RSV infection of the airway epithelial cells can associated with an increased biofilm formation after culture coincubation with Pseudomonas aeruginosa (14). The novel molecular diagnostic tests allow a better detection in revealing viral infections in asthma exacerbations reaching up a frequency to $80 \%$ (15). In both asthma and COPD exacerbations, rhino- and influenza viral infections are associated with a higher risk of frequent hospitalization $(7,16,17)$. These data sustain the pathogenic role of chronic viral infection in asthmatics and COPD patients, highlighting the appropriateness and the effectiveness of antiviral therapies.

\section{Antiviral therapy, a therapeutic approach in asthma/COPD exacerhators?}

In influenza, AH1N1 pandemics, antivirals are most effective if promptly started, within the first 48 hours from the onset of disease (18). According to the type of viral strains, the severity of illness and the safety profile of the drug are different. Antiviral therapy is the earliest opportunity to reduce the risk of respiratory failure or death, especially, in hospitalized patients with progressive or complicated influenza.

Ribavirin is a nucleoside analogue, extensively used in patients with viral hepatitis C, children or lung transplant recipients with RSV infection (19), because it can interfere with viral strain multiplication. Its inhaled formulation was evaluated as safe in elderly patients with stable
COPD (20).

M2 ion channel blockers (adamantanes): rimantadine and amantadine, currently, used as anti-Parkinson drugs, can inhibit the replication of influenza type A virus, have no effect on type $\mathrm{B}$, poor safety profile, inducing rapid selection of resistance $(21,22)$.

Neuraminidase inhibitors, more recently developed to treat and prevent influenza A and $\mathrm{B}$, are represented by oseltamivir and zanamivir, widely, available, and perinamivir and laninamivir, with circumscribed availability.

Oseltamivir (Tamiflu ${ }^{\circledR}$ ) is a prodrug activated, after liver passage, to oseltamivir carboxylate which inhibits the viral neuraminidase A, with consequent releasing of virions (23). Standard dosages of $75 \mathrm{mg}$ /day or $150 \mathrm{mg}$ /day showed efficacy in reducing the risk of pneumonia, illness severity and duration $(24,25)$.

Zanamivir (Relenza $\left.{ }^{\circledR}\right)$, used for prophylaxis or cure of influenza $A$ and $B$ infections, 5 days regimen of $10 \mathrm{mg}$ inhaled twice daily, reveals an earlier reduction in symptoms score (26), lower risk of bronchitis in adults (27) and lower rate of bacterial complications requiring antibiotic use (28).

Peramivir (Rapivab $\left.{ }^{\circledR}\right)$, a newer neuraminidase inhibitor, which inhibits the release of virions of influenza A and B, was, initially, developed as an oral formulation with a low bioavailability and, later, as a parenteral intravenous formulation given once daily, and tested, with efficacy, in critically ill patients $(29,30)$.

Oseltamivir and zaninamivir were successfully used during AH1N1 pandemics.

Laninamivir is a long-acting neuraminidase inhibitor active against influenza $\mathrm{A}$ and $\mathrm{B}$, including oseltamivir resistant strains, recently tested as inhaled formulation, delivered via dry powder, once daily, with efficacy analysis in 996 patients proving non-inferiority versus oseltamivir from the perspective of potential gastrointestinal side effects (31).

Other investigational compounds consist in new viral therapeutic targets (capsid structural proteins or C3 proteases), which allow the development of other antiviral therapies [pleconaril (capsid inhibitor) or rupintrivir (C3 
protease inhibitor); RNA polymerase inhibitors, such as favipiravir], some of them still investigated for hepatitis $\mathrm{C}$ and Ebola virus, or authorized, in Japan, for influenza therapy $(32,33)$. Monoclonal antibodies and interferons alpha, beta, gamma, lambda raised the interest as potential antiviral therapies for various respiratory infections $(34,35)$.

\section{Conclusion}

In conclusion, the therapeutic role of antivirals in exacerbations of asthma/COPD is still unclear. There are limited data on the effectiveness in asthma/COPD exacerbations, insufficient knowledge of subset categories of illness, which could benefit of the antivirals addition to the conventional therapeutic recommendations, and lack of clear indications. The first problem can be solved by future clinical trials assessing of neuraminidase inhibitors or monoclonal antibodies in COPD viral exacerbations as curative therapies. Antiviral therapy can improve outcomes of OLD exacerbations such as reduced mortality risk, reduced intensive care unit (ICU) and/or hospital admission, reduced in hospital respiratory failure risk, and the last, but not the least, reduced hospitalization duration. The impact of viral infections on COPD exacerbation is more important than on asthma exacerbation. It is not clear if antivirals can be universally indicated in any asthma/COPD exacerbations. An important step ahead would be the identification of a reliable biomarker of impaired innate immunity in patients with frequent exacerbations. Although viral infections can increased the OLD morbidity and mortality, current guidelines are focused more on preventing influenza than treating.

\section{References}

1. Mihailov C, Jimborean G, Rascu A, Arghir, OC. The Impact of Tobacco Smoke Exposure on Asthma COPD-Like Patients. J. Environ. Prot. Ecol. 2016;17(4), 1523-1523.

2. Dantes E, Man MA, Arghir OA,Alexandrescu D, Trofor A. Risk factors and overlap between asthma and chronic obstructive pulmonary disease. Proceedings of the International Conference on Risk Management,
Assessment and Mitigation, RIMA '10; WSEAS Conference Book „RECENT ADVANCES IN RISK MANAGEMENT, ASSESSMENT AND MITIGATION" Australia WSEAS Press. 2010;369-373.

3. Rascu A, Popa DE, Arghir OC, Naghi E. Effects of Corticosteroid Treatment on Respiratory Muscles Function in Patients with Severe Obstructive Lung Disease, FARMACIA. 2016; 64(6):819-822.

4. Biancardi E, Fennell M, Rawlinson W, Thomas PS. Viruses are frequently present as the infecting agent in acute exacerbations of chronic obstructive pulmonary disease in patients presenting to hospital. Int. Med. J. 2016;46, 1160-1165.

5. Mohan A, Chandra S, Agarwal D, Guleria R, Broor S, Gaur B, Pandey RM. Prevalence of viral infection detected by PCR and RTPCR in patients with acute exacerbation of COPD: a systematic review. Respirology. 2010;15, 536-542.

6. Johnston SL, Pattemore PK, Sanderson G, Smith S, Lampe F, et al. Community study of role of viral infections in exacerbations of asthma in 9-11 year old children. BMJ. 1995;310:1225-1229.

7. Edwards MR, Kebadze T, Johnson MW, Johnston SL. New treatment regimens for virus-induced exacerbations of asthma. Pulm. Pharmacol. Ther. 2006;19, 320-334.

8. Cambrea SC, Halichidis S, Mihai CM, Carp DS, Stoicescu RM, ArghirOC. Environmental risk factors for influenza AH1N1 among children in south-east Romania, J. Environ. Prot. Ecol. 2013;14(3):1132-1139.

9. Welte T, Miravitlles M. Viral, bacterial or both? Regardless, we need to treat infection in COPD. Eur. Respir. J. 2014;44:11-13.

10. Saleh A, López-Campos JL, Hartl S, et al. The Effect of Incidental Consolidation on Management and Outcomes in COPD Exacerbations: Data from the European COPD Audit, PLos One. 2015;10(7), e0134004.

11. López-Campos JL, Hartl S, Pozo-Rodríguez F, et al. Antibiotic Prescription for COPD Exacerbations Admitted to Hospital: European COPD Audit. PLos One, 2015;10(4), e0124374. 
12. Seemungal T, Harper-Owen R, Bhowmik A, et al. Respiratory Viruses, Symptoms, and Inflammatory MarkersinAcuteExacerbations and Stable Chronic Obstructive Pulmonary Disease. Am. J. Respir. Crit. Care Med. 2001;164:1618-1623.

13. Oliver BG, Lim S, Wark $P$, et al. Rhinovirus exposure impairs immune responses to bacterial products in human alveolar macrophages. Thorax. 2008;63:519-525.

14. Hendricks MR, Lashua LP, Fischer DK, et al. Respiratory syncytial virus infection enhances Pseudomonas aeruginosa biofilm growth through dysregulation of nutritional immunity. Proc. Natl, Acad. Sci. U S A, 2016;113:1642-1647.

15. Nicholson KG, Kent J, Ireland DC. Respiratory viruses and exacerbations of asthma in adults. BMJ, 1993;307:982-986.

16. Green RM, Custovic A, Sanderson G, Hunter J, Johnston SL, Woodcock A. Synergism between allergens and viruses and risk of hospital admission with asthma: case-control study. BMJ. 2002;324:1-5.

17. Wark PAB, Tooze $\mathrm{M}$, Powell $\mathrm{H}$, et al. Viral and bacterial infection in acute asthma and chronic obstructive pulmonary disease increases the risk of readmission. Respirology. 2013;18, 996-1002.

18. Rewar S, Mirdha D, Rewar P. Treatment and Prevention of Pandemic H1N1 Influenza. Ann. Glob. Health. 2015;81:645-653.

19. Pelaez A, Lyon GM, Force SD, et al. Efficacy of Oral Ribavirin in Lung Transplant Patients with Respiratory Syncytial Virus Lower Respiratory Tract Infection. J. Heart Lung Transplant, 2009;28:67-71.

20. Liss HP, Bernstein J. Ribavirin Aerosol in the Elderly. Chest. 1998;93:1239-1241.

21. Nathan RA, Geddes D, Woodhead M. Management of influenza in patients with asthma or chronic obstructive pulmonary disease. Ann. Allergy Asthma Immunol. 2001;87:447-454.

22. Hayden FG, Belshe RB, Clover RD, et al. Emergence and Apparent Transmission of Rimantadine-Resistant Influenza A Virus in Families. N. Engl. J. Med. 1989;321:16961702.

23. Davies

$$
\text { B.E. }
$$

Pharmacokinetics oseltamivir: an oral antiviral for the treatment and prophylaxis of influenza in diverse populations. J. Antimicrob. Chemother. 2010;65:ii5-ii10.

24. Jefferson $\mathrm{T}$, Jones $\mathrm{M}$, Doshi $\mathrm{P}$, et al. Oseltamivir for influenza in adults and children: systematic review of clinical study reports and summary of regulatory comments. BMJ. 2014; 348:g2545.

25. Treanor JJ, Hayden FG, Vrooman PS, et al. Efficacy and safety of the oral neuraminidase inhibitor oseltamivir in treating acute influenza: A randomized controlled trial. JAMA. 2000;283:1016-1024.

26. MontoAS, WebsterA, Keene O. Randomized, placebo-controlled studies of inhaled zanamivir in the treatment of influenza $A$ and B: pooled efficacy analysis. J. Antimicrob. Chemother. 1999;44:23-29.

27. Heneghan CJ, Onakpoya I, Thompson M, et al. Zanamivir for influenza in adults and children: systematic review of clinical study reports and summary of regulatory comments. BMJ. 2014;348:g2547.

28. Lalezari J, Campion K, Keene O, et al. Zanamivir for the treatment of influenza $\mathrm{a}$ and $\mathrm{b}$ infection in high-risk patients: A pooled analysis of randomized controlled trials. Arch. Intern. Med.2001;161:212-217.

29. Wester A, Shetty AK. Peramivir injection in the treatment of acute influenza: a review of the literature. Infect. Drug Resist. 2016;9:201-214.

30. Kohno S, Kida H, Mizuguchi M, et al. Efficacy and safety of intravenous peramivir for treatment of seasonal influenza virus infection. J. Antimicrob. Agents Chemother. 2010; 54(11):4568-4574.

31. Watanabe A, Chang SC, Kim MJ, et al. Longacting neuraminidase inhibitor laninamivir octanoate versus oseltamivir for treatment of influenza: A double-blind, randomized, noninferiority clinical trial. Clin. Infect. Dis. 2010;51:1167-1175.

32. Smee DF, Tarbet EB, Furuta $Y$, et al. Synergistic combinations of favipiravir and oseltamivir against wild-type pandemic and oseltamivir-resistant influenza $\mathrm{A}$ virus infections in mice. Future Virol. 2013;8:10851094. 
33. Furuta Y, Gowen BB, Takahashi K, et al. Favipiravir (T-705), a novel viral RNA polymerase inhibitor. Antiviral Res. 2013;100:446-454.

34. Berry CM. Understanding Interferon Subtype Therapy for Viral Infections: Harnessing the Power of the Innate Immune System. Cytokine Growth Factor Rev. 2016;31:8390.

35. Kim S, Kim MJ, Kim $\mathrm{CH}$, et al. The Superiority of IFN-lambda as a Therapeutic Candidate to Control Acute Influenza Viral Lung Infection. Am. J. Respir. Cell Mol. Biol. 2017; 56(2):202-212. 